\title{
PENGARUH CACAT LAS PADA SAMBUNGAN PIPA BAWAH LAUT (GIRTH WELD) DENGAN MENGAPLIKASIKAN FAILURE ANALYSIS DIAGRAM (FAD)
}

\author{
Suyadi \\ Program Studi D III Teknik Perkapalan \\ Fakultas Teknik Universitas Diponegoro
}

\begin{abstract}
Suyadi, An under sea pipe connection (girth weld) is an area that possibly will get defect. This weld defects have a potential for causing tension concentration, so that there will be preliminary crack. This crack will spread due to cyclic loads received by the structure. This final assignment research is performed for evaluating mechanical integrity and girth weld having weld defect using method of Failure Analysis Diagram (FAD) and it takes a sample of case for South Sumatra West Java pipe belongs to PGN Co.Ltd. FAD is a method, which is good enough for evaluating the integrity of pipe structure having crack like flaw upon the weld. FAD divides two areas, namely safe area and unsafe area constructed by two axis, namely $x$ axis that is stress ratio $(\mathrm{Lr})$ and $y$ axis that is stress intensity ratio $(\mathrm{Kr})$. Stress ratio $(\mathrm{Lr})$ is a ratio between a ref and a yield, mean while stress intensity ratio $(K r)$ is a ratio (stress intensity factor) between $K l$ and $K_{I C}$ (fracture toughness material). ANSYS 8.0 software is used for modeling by considering that the defect is in the form of semi elliptic with a/2c variation, that is 0,0469; 0,0938; 0,01406; and 0,1750. The loading upon the pipe is considered as the minimum loading (opull $=8284.25$ psi), medium $($ opull $=41421.25$ psi $)$ and maximum $($ opull $=82842.5$ psi $)$. From the analysis result, it is obtained that crack dimension with a/2c 0.175 is not safe upon minimum and medium loading, mean while upon the maximum loading condition, all modeled cracks dimensions cause the pipe is not safe.
\end{abstract}

Keywords : pipeline, girth weld, semi elliptical defect, FAD.

\section{PENDAHULUAN}

Penggunaan pipa bawah laut (subsea pipeline) pada industri lepas pantai sebagai salah satu alternatif transportasi fluida (gas, minyak, LNG, dll) selain menggunakan kapal tanker dalam beberapa kurun waktu terakhir mengalami peningkatan. Hal tersebut diperkuat dengan banyaknya penemuan sumber-sumber minyak baru, baik di laut dalam maupun dangkal yang dalam proses eksploitasi, produksi dan transportasi fluida tidak akan lepas dari penggunaan pipa bawah laut. Penggunaan pipa bawah laut sebagai alat transportasi fluida dianggap lebih efisien dan lebih aman daripada tanker, sehingga banyak digunakan. Di Indonesia sendiri pada bulan Agustus 2003 telah diresmikan penggunaan pipa gas alam PT PGN sepanjang $477 \mathrm{~km}$ (Offshore $212 \mathrm{~km}$ dia. 28") yang memasok gas alam $(600 \mathrm{mmcf} / \mathrm{d})$ dengan operator Conoco Philips dari gresik, Sumatera Selatan ke Singapura lewat Kuala Tungkal dan Batam dengan biaya US\$420 juta (Soegiono. 2004).

Sejak tahun 1995 BP dari pulau Pagerungan memasok gas alam ke Gresik untuk PT PLN, PT PGN, PT Semen Gresik dan PT Petrokimia melalui pipa bawah laut (subsea pipeline) dengan diameter 28 inch sepanjang $364 \mathrm{~km}$ (onshore $62 \mathrm{~km}$, berat baja total 112.630 ton, biaya US\$432 juta). Pada tahun 2006 ini, akan mulai dikerjakan proyek pipanisasi gas dari Kalimantan Timur ke Jawa Timur oleh PT PGN, panjang onshore $400 \mathrm{~km}$ dan offshore sepanjang $370 \mathrm{~km}$ dengan kapasitas 70010000 MMSCFD, akan dikerjakan selama dua tahun dengan biaya sekitar US\$1.7 milyar. Dikarenakan banyaknya penggunaan pipa bawah laut untuk transportasi fluida, khususnya untuk transportasi gas, maka suatu metode untuk mengevaluasi integritas struktur pipa tersebut sangat penting untuk mengetahui kondisi suatu pipa apakah masih layak beroperasi atau tidak.

Evalusi integritas pipa dengan menggunakan pendekatan fracture mechanics dengan mengaplikasikan Failure Analysis Diagram (FAD) merupakan salah satu metode yang cukup handal untuk mengevaluasi integritas pada girth weld. FAD akan menghasilkan beberapa keputusan yang tepat terhadap pipa, sehingga dapat menjadi acuan bagi para ahli teknik perpipaan dalam mengambil kebijakan terhadap pipa yang dianalisis, misalnya run-rerate-repair replacement.

\section{DASAR TEORI}

\section{Jenis Cacat Pengelasan}

Jenis cacat yang sering terjadi pada daerah girth weld pada umumnya adalah cacat permukaan las yang berbentuk cacat undercut (Gambar 1). Cacat permukaan biasanya berbentuk retak semi eliptik, sehingga geometri cacat undercut dapat didekati dengan model cacat semi eliptik. Posisi cacat pada contoh di atas pada girth weld pipeline dilihat dari arah sumbu aksial dengan geometri dan ukuran tertentu. Khusus untuk pipa gas bertekanan tinggi cacat seperti ini sangat membahayakan. Pada saat dilakukan hidrostatic test awal, sering kali cacat ini menyebabkan pipa bocor. Namun sering 
kali terjadi karena cacat ini belum tumbuh mencapai ukuran kritisnya, maka pada saat hidrostatic test awal cacat ini belum terlihat, namun akan terjadi pertumbuhan cacat apabila pipa dialiri gas yang bertekanan tinggi. Sehingga apabila suatu girth weld pipeline mempunyai cacat, maka harus segera dianalisis sesegera mungkin sehingga dapat diambil keputusan yang tepat terhadap pipa tersebut.

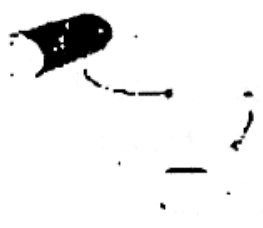

1,1

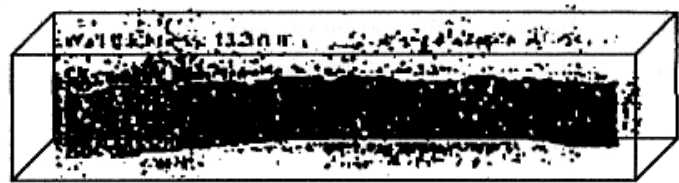

Gambar 1. Cacat Undercut bentuk Semi Eliptik

\section{Mekanika Kepecahan (Fracture Mechanics) Analisis Tegangan}

Analisis tegangan yang menyebabkan kepecahan dari komponen yang mempunyai crack yaitu didasakan pada konsep teori elastisitas. Dengan mengidentifikasi metode yang dikembangkan oleh Westergaard, Irwine mengemukakan pemecahan masalah tentang analisis distribusi tegangan pada crack dengan menggunakan tiga model pembebanan utama. Setiap model pembebanan mempunyai perbedaan pada crack dipermukaannya. Secara visual ketiga jenis model bentuk tersebut diperlihatkan pada Gambar 2. Model pembebanan pada permukaan retak yaitu :

- Model I, Opening atau tensile mode, dimana cacat dipermukaan berjalan dengan cepat.

- Model II, Sliding atau in plane shear mode, dimana permukaan crack saling terjadi sliding yang berlawanan arah satu dengan yang lainnya.

- Model III, Tearing atau antiplane shear mode, dimana permukaan crack bergerak relatif satu dengan yang lainnya.
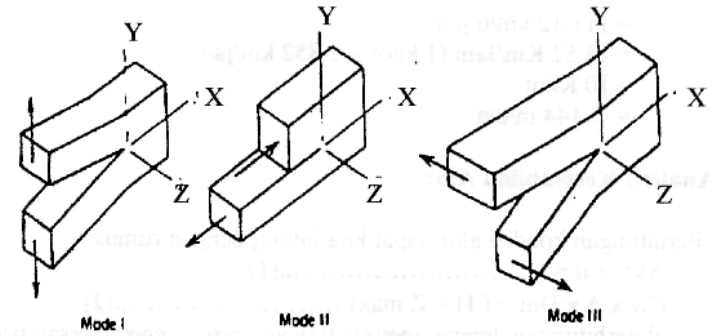

Gambar 2. Model Pembebanan pada Permukaan Retak
Untuk mode I, medan tegangan terjadi pada kondisi sebagaimana digambarkan oleh persamaan (1)

$$
\begin{aligned}
& \sigma_{x}=\frac{K_{1}}{\sqrt{2 \pi r}} \cos \frac{\theta}{2}\left[1-\sin \frac{\theta}{2} \sin \frac{3 \theta}{2}\right] \\
& \sigma_{y}=\frac{K_{1}}{\sqrt{2 \pi r}} \cos \frac{\theta}{2}\left[1-\sin \frac{\theta}{2} \sin \frac{3 \theta}{2}\right] \\
& \tau_{x y}=\frac{K_{1}}{\sqrt{2 \pi r}} \cos \frac{\theta}{2}\left[1-\sin \frac{\theta}{2} \sin \frac{3 \theta}{2}\right] \\
& \tau_{x z}=\tau_{y z}=0 \\
& \sigma_{z}=v\left(\sigma_{y}+\sigma_{y}\right) \\
& u=\frac{K_{1}}{G}\left[\frac{r}{2 \pi}\right]^{1 / 2} \cos \frac{\theta}{2}\left[1-2 v+\sin ^{2} \frac{\theta}{2}\right] \\
& v=\frac{K_{1}}{G}\left[\frac{r}{2 \pi}\right]^{1 / 2} \sin \frac{\theta}{2}\left[2-2 v+\sin ^{2} \frac{\theta}{2}\right] \\
& \mathrm{w}=0
\end{aligned}
$$

\section{Faktor Intensitas Tegangan (Stress Intensity Factor-IF)}

Dalam ilmu mekanika kepecahan, terdapat salah satu parameter yang sangat penting yaitu SIF. SIF yang merupakan parameter untuk menentukan medan tegangan yang terjadi di sekitar ujung retak jika suatu struktur yang terdapat retakan tersebut dikenai beban.

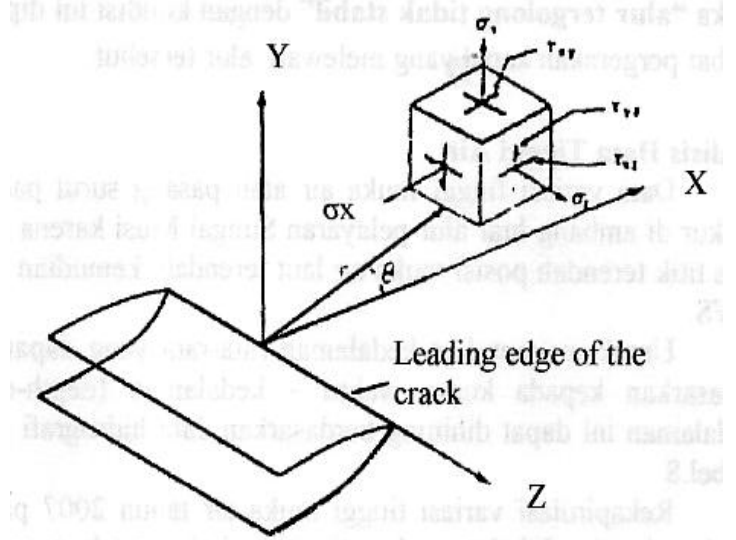

Gambar 3. Distribusi tegangan disekitar ujung retak

Persamaan umum untuk SIF secara umum adalah seperti pada Persamaan (2).

$$
K=Y \sqrt{\pi \cdot a} \times \sigma
$$

Keterangan :

$$
\begin{aligned}
\mathrm{K}= & \mathrm{SIF} \\
\mathrm{a}= & \text { panjang retak awal } \\
\mathrm{Y}= & \text { fungsi koreksi terhadap dimensi dan } \\
& \text { geometri serta posisi dari retak } \\
\sigma= & \text { Tegangan pada retak }
\end{aligned}
$$

Menurut Anderson (1995), perhitungan stress intensity factor untuk crack yang semi eliptic (Gambar 4) dengan variasi a dan c, adalah sebagai berikut : 


$$
K_{1}=\sigma \cdot \sqrt{\pi a / Q} \cdot F_{t}
$$

Dimana :

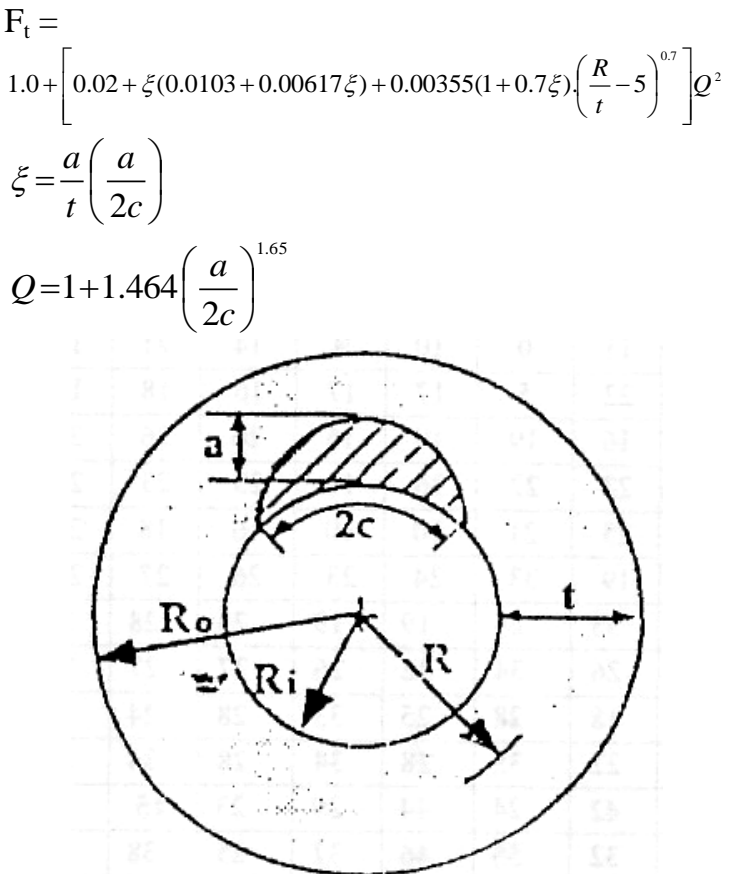

Gambar 4. Cacat Semi Eliptik Pada Pipa (sumber: Fracture Mechanics : Fundamental and Aplication, 1995)

\section{Ketangguhan Material I Fracture Toughness of Material}

Ketangguhan / Fracture Toughness dari material adalah kemampuan material terhadap untuk menahan besarnya SIF pada ujung retak agar tidak terjadi pertambahan panjang retak. Untuk memperoleh nilai dari ketangguhan material yang valid yaitu dengan melakukan pengujian di Laboratorium. Dikarenakan data $\mathrm{K}_{\mathrm{IC}}$ dari hasil pengujian untuk material tertentu tidak banyak tersedia, maka para peneliti banyak menggunakan pendekatan dengan rumus empiris untuk mengestimasi berapa besarnya nilai dari Fracture Toughness of Material.

Menurut Barsom dan Rolfe (1987), perhitungan Fracture Toughness material $\left(\mathrm{K}_{\mathrm{IC}}\right)$ dapat dihitung dengan menggunakan hasil pengujian impact charpy (CVN), yaitu dengan menggunakan persamaan sebagai berikut:

$$
\left(\frac{K_{I C}}{\sigma_{y s}}\right)=5\left(\frac{C V N}{\sigma_{y s}}-0.05\right)
$$

Dimana CVN menurut API 5L (2000) diperoleh dari nilai yang disyaratkan yaitu untuk pipa dengan grade dibawah X-80, maka nilai CVN materialnya adalah $30 \mathrm{ft}-\mathrm{lb}$ atau dengan pendekatan persamaan berikut:

$$
C V N=0.000512 \cdot\left(\mathrm{F} \sigma_{\mathrm{y}}\right)^{3 / 2}\left(\frac{D}{2}\right)^{1 / 2}
$$

Keterangan :

$$
\begin{aligned}
& \mathrm{K}_{\mathrm{IC}}=\text { Fracture Toughness material } \\
& \sigma_{\mathrm{y}}=\text { sigma YS } \\
& \mathrm{F} \quad \text { stress factor }(0.72) \\
& \mathrm{D}=\text { Outer Diameter of pipe }
\end{aligned}
$$

\section{Failure Analysis Diagram (FAD)}

Failure Analysis Diagram adalah suatu metode untuk mengevaluasi integritas struktur pipa yang memiliki jenis cacat (crack, like, flaw) pada lasan (girth weld pipeline). Metode ini pada awalnya hanya menggunakan dasar perhitungan mekanika retak, yang kemudian dipopulerkan oleh API RP 579. Menurut sejarahnya, prosedur evaluasi integritas struktur pada mulanya diusulkan oleh Central Electricity Generating Board (CEGB) di Inggris pada tahun 1976. Dengan menggunakan model strip yield dari Dudgale yang dapat diterapkan pada material "elastic perfecty plastic" prosedur ini dikenalkan, namun metode ini kemudian dikembangkan untuk material dengan perilaku strain hardening yang menggantikan yield stress dengan flow stress. Flow stress adalah harga rata-rata dari yield stress dan tensile stress.

Penggunan FAD berkaitan erat dengan perencanaan inspeksi dan perawatan, FAD dapat menjadi metode yang cukup efektif untuk membantu para ahli teknik dalam mengambil keputusan yang tepat, apakah pipa cacat harus diperbaiki, diganti, ataukah tetap digunakan untuk beroperasi. Setiap section sambungan lasan pipa (girth weld) yang mempunyai cacat masing-masing dievaluasi dan hasilnya dimasukkan dalam FAD, sehingga akan terlihat section mana yang aman, relatif aman, atau yang tidak aman dan perlu dilakukan pergantian. Keputusan yang banyak diambil adalah derating / down grade, yaitu walaupun girth weld mempunyai cacat dengan dimensi tertentu, akan tetapi pipa tetap dioperasikan tanpa ada perbaikan, hanya saja beban operasinya yang dikurangi.

\section{METODOLOGI}

\section{Diagram Alir Penelitian}

Alur analisis Integritas Struktur pipa dengan FAD (Failure Analysis Diagram) dapat dilihat pada Gambar 5.

Failure Analysis Diagram ini dibangun dari dua sumbu, untuk sumbu $\mathrm{x}$ memperlihatkan perbandingan antara tegangan operasi dari material pipa dan kuat luluh material itu sendiri (stress ratioLr), sedangkan untuk sumbu y dari FAD ini adalah memperlihatkan perbandingan faktor intensitas tegangan dengan ketangguhan dari material itu (stress Intensity ratio $(\mathrm{Kr})$ ).

\section{Stress Intensity Rasio (Kr)}

Perbandingan antara faktor intensitas tegangan dengan ketangguhan material menunjukkan sejauh mana kehadiran cacat dengan dimensi tertentu pada 
material dapat mempengaruhi ketangguhan material tersebut. Dalam FAD, Kr digunakan dalam salah satu sumbu yang nantinya berfungsi untuk mengevaluasi material. Kondisi patah getas akan terjadi apabila $\mathrm{Kr}$ bernilai lebih besar dari 1. Hal ini ditunjukkan dengan material sudah tidak dapat menahan beban yang mengenainya, yang berarti bahwa kehadiran cacat akan menyebabkan kegagalan pada material.

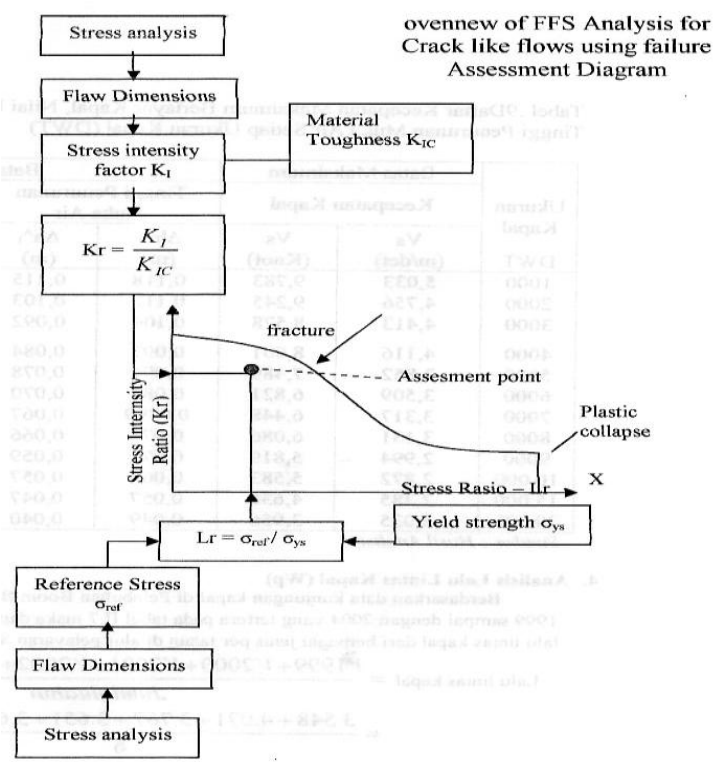

Gambar 5. Alur Penyelesaian FAD (sumber : Indonesian Pipeline Technology, 2004)

$$
K_{r}=\frac{K_{l}}{K}
$$

\section{Stress Rasio (Lr)}

Ujung retak merupakan daerah yang sangat kritis, karena di daerah tersebut terjadi konsentrasi tegangan yang cukup tinggi. Tegangan yang berada di ujuag retak sangat besar sehingga akan mempengaruhi perambatan retak. Selain itu besarnya tegangan di ujung retak tersebut dapat digunakan untuk memberikan informasi tentang kekuatan pipa terhadap beban yang mengenainya. Oleh karena perhitungan tegangan di ujung retak sangat penting.

Perhitungan tersebut selanjutnya digunakan untuk menghitung stress ratio, yaitu rasio antara tegangan dan kuat material yang berfungsi untuk mengetahui bagaimana peluang material pipa dapat mengalami plastic collapse untuk kemudian dimasukkan dalam failure Analysis Diagram untuk melakukan evaluasi terhadap pipa. Rasio antara tegangan dan kuat material (Lr) dituliskan sebagai berikut :

$$
L_{r}=\frac{\sigma_{r e f}}{\sigma_{y s}}
$$

Keterangan :

$$
\begin{aligned}
& \sigma_{\text {ref }}=\text { Tegangan Referensi } \\
& \sigma_{\mathrm{ys}}=\text { Tegangan Yield Material }
\end{aligned}
$$

Dari dua kriteria tersebut maka akan digunakan untuk memprediksi kehandalan dan integritas pipa serta modus kegagalan (failure mode) dari pipeline, antara lain: patah getas (brittle fracture), deformasi plastis (plastic collapse), ataupun gabungan antara keduanya (mixed mode). Penentuan apakah struktur pipa tersebut aman atau tidak terhadap ketiga jenis model kegagalan yaitu dilihat dari gabungan antara tegangan (stress), geometri dan dimensi cacat (geometric and flaw dimensions), kuat luluh (yield strength),dan ketangguhan material (material toughness).

Dari hasil analisis pipa dengan FAD, diharapkan keputusan run-rerate-repair-replacement pada pipa bawah laut dapat dilakukan.

- Keputusan run diambil apabila hasil analisis FAD menunjukkan posisi dari fungsi $\mathrm{Kr}$ dan Lr masih berada dibawah assessment line yaitu pada daerah aman, sehingga pipa akan diijinkan untuk terus beroperasi.

- Keputusan repair diambil apabila hasil analisis FAD menunjukkan posisi dari fungsi $\mathrm{Kr}$ dan Lr berada diatas assessment line bagian kanan bawah yaitu pada daerah tidak aman (plastic collapse), sehingga pipa akan mengalami kebocoran dan harus diperbaiki.

- Keputusan rerate diambil apabila hasil analisis FAD menunjukkan posisi dari fungsi $\mathrm{Kr}$ dan Lr berada diatas assessment line bagian tengah yaitu pada daerah pertengahan kegagalan yang ditandai dengan mixed mode, sehingga pipa akan diijinkan untuk terus beroperasi dengan mengurangi beban operasinya tanpa melakukan perbaikan.

- Keputusan replacement diambil apabila hasil analisis FAD menunjukkan posisi dari fungsi $\mathrm{Kr}$ dan $\mathrm{Lr}$ masih berada diatas assessment line bagian kiri atas yaitu pada daerah tidak aman (brittle failure), sehingga keputusan pergantian pipa sangat penting karena apabila terus beroperasi pipa akan pecah dan meledak.

\section{PEMODELAN STRUKTUR}

\section{Geometri Struktur}

Pemodelan struktur pipa dilakukan dengan bantuan software ANSYS 8.0 yang merupakan salah satu tool untuk melakukan analisis lokal pada suatu struktur dengan pendekatan Finite Elemen Methode. Oleh karena itu pemodelan yang dilakukan yaitu dengan memotong geometri pipa menjadi seperempat bagian. Pemodelan dilakukan sebanyak 5 kali dengan variasi besarnya dimensi cacat. Geometri model lasan pipa dibuat berdasarkan pada rule-rule umum yang berlaku pada fabrikasi. Geometri lasan pipa yang dimodelkan adalah terlihat pada Gambar 6 berikut: 


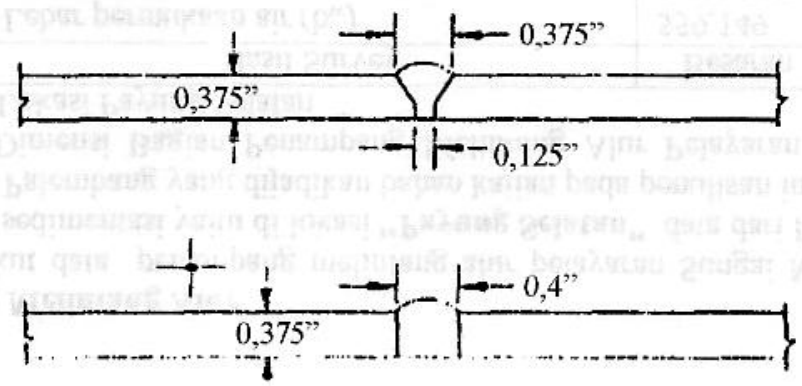

Gambar 6. Geometri Lasan Pipa

Untuk pemodelan cacat las undercut dilakukan dengan membentuk geometri semi eliptik yang berada di area geometri las pipa dengan membuat koordinat yang sesuai dengan ukuran cacat las yang akan dimodelkan. Untuk tampilan isometris dari pemodelan dapat dilihat pada Gambar 7.

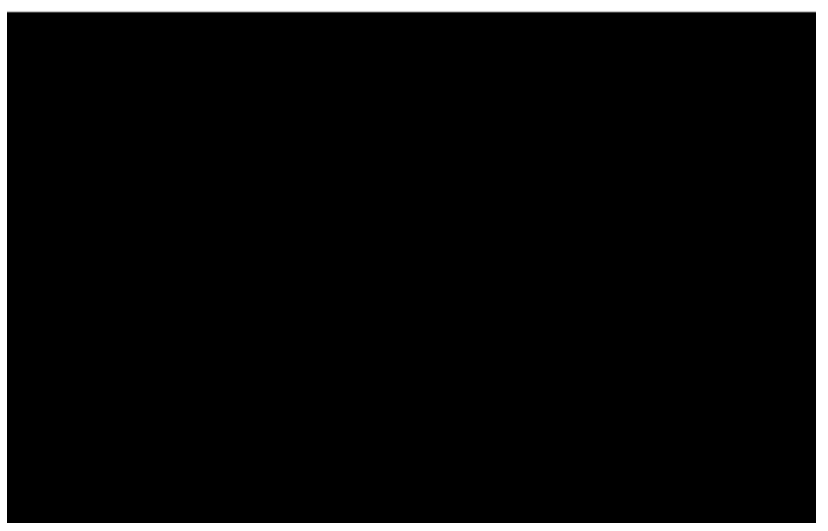

Gembar 7. Model Isometrik Pipa SSWJ PT PGN

Untuk pemodelan cacat semi eliptik dilakukan dengan memodelkan bentuk cacat setengah dari cacat semi eliptik dengan memberikan boundary yang sama seperti pemodelan full retak semi eliptik. Hal ini dilakukan untuk menghemat memori dan memperpendek running time.

\section{Meshing Model}

Dalam pemodelan yang telah dilakukan, meshing model dilakukan dengan menggunakan solid 95, brick element 20 nodes. Dengan menggunakan elemen solid 95, maka elemen yang dimodelkan dapat berbentuk tidak teratur sebagaimana digunakan untuk meshing cacat semi eliptik tanpa mengurangi keakuratannya. Elemen ini mempunyai 3 derajat kebebasan (three degree of freedom) pada tiap node dan translasi ke arah sumbu X, Y, dan Z per-nodal.

\section{ANALISIS DAN PEMBAHASAN \\ Validasi Model}

Validasi model dilakukan dengan membandingkan hasil output dari software ANSYS 8.0 dengan hasil perhitungan men.ggunakan
Persamaan (3). Sebagai contoh adalah proses validasi pada kondisi pembebanan minimum. Perbandingan nilai SIF ini dapat dilihat pada Tabel 1. Dan tabel tersebut dapat dilihat bahwa kesalahan (error) rata-rata sebesar $0.609 \%$ dan kesalahan maksimum sebesar $0.797 \%$.

Tabel 1. Validasi Model pada Pembebanan Minimum

\begin{tabular}{cccc}
\hline $\begin{array}{c}\text { a/2c } \\
\text { (inch) }\end{array}$ & $\begin{array}{c}\text { K1 } \\
(\text { Anderson) } \\
(\mathbf{k s i} \sqrt{\text { in }})\end{array}$ & $\begin{array}{c}\text { K1 (model) } \\
(\mathbf{k s i} \sqrt{\text { in }})\end{array}$ & koreksi \\
\hline 0.0469 & 24.593 & 24.449 & $0.584 \%$ \\
0.0938 & 47.625 & 47.415 & $0.442 \%$ \\
0.1406 & 79.243 & 78.757 & $0.613 \%$ \\
0.1750 & 147.321 & 146.147 & $0.797 \%$ \\
\hline
\end{tabular}

FAD Kondisi Pembebanan Minimum $\left(\sigma_{\text {tarik }}=\right.$ 8284.25 psi)

Dalam perhitungan ini nilai $\mathrm{Kr}$ terbesar yang didapatkan adalah 1.0933, dengan nilai dari masing-masing $\mathrm{Kr}$ menurut variasi cacatnya adalah 0.1829; 0.3547; 0.5892; dan 1.0933. Sehingga, besarnya cacat tersebut akan mempengaruhi material pipa. Apabila kita lihat pada kondisi pipa, dikarenakan harga $\mathrm{Kr}$ selalu naik berdasarkan kenaikan a/2c dari cacat yang terjadi. Hasil dari perhitungan $\mathrm{Kr}$ dan $\mathrm{Lr}$ dapat dilihat pada tabel 2.

Tabel 2. Perhitungan Kr dan Lr Pada Pembebanan Minimum

\begin{tabular}{cccc}
\hline $\begin{array}{c}\text { crack } \\
\text { junction }\end{array}$ & a/2c (inch) & Kr & Lr \\
\hline A & 0.0469 & 0.1829 & 0.1269 \\
B & 0.0938 & 0.3547 & 0.1269 \\
C & 0.1406 & 0.5892 & 0.1269 \\
D & 0.1750 & 1.0933 & 0.1269 \\
\hline
\end{tabular}

Dari perhitungan diketahui bahwa nilai $\mathrm{Lr}$ adalah 0.1269 , yang masing-masing nilainya adalah sama. Hal ini terjadi dikarenakan besarnya tegangan tarik yang dibebankan pada struktur dan tegangan yield yang dimiliki oleh material adalah tetap, yaitu masing-masing sebesar 8284.25 psi dan 63000 psi. Dari FAD didapatkan bahwa, pipa gas bawah laut SSWJ milik PT PGN, apabila mempunyai beberapa cacat dengan dimensi $\mathrm{a} / 2 \mathrm{c}=$ 0.175 yang akan menyebabkan kegagalan pada pipa berupa brittle collapse yang artinya akan tejadi patah getas. Hal ini tejadi dikarenakan posisi $\mathrm{Kr}$ dan Lr menurut FAD berada pada daerah brittle failure diatas assesment line. Sedangkan untuk dimensi cacat yang lebih kecil masih pada kondisi aman.

\section{FAD Kondisi Pembebanan Menengah $\left(\sigma_{\mathrm{tarik}}=\right.$ 41421.25 psi) \\ Hasil dari perhitungan $\mathrm{Kr}$ dan $\mathrm{Lr}$ dapat dilihat pada Tabel 3 .}


Tabel 3. Perhitungan Kr dan Lr pada Pembebanan Menengah

\begin{tabular}{cccc}
\hline $\begin{array}{c}\text { crack } \\
\text { junction }\end{array}$ & $\mathbf{a} / \mathbf{2 c}$ (inch) & Kr & Lr \\
\hline A & 0.0469 & 0.2849 & 0.6343 \\
B & 0.0938 & 0.5036 & 0.6343 \\
C & 0.1406 & 0.7273 & 0.6343 \\
D & 0.1750 & 1.2167 & 0.6343 \\
\hline
\end{tabular}

Dari FAD di atas didapatkan bahwa, pipa gas bawah laut yang mempunyai cacat dengan dimensi $\mathrm{a} / 2 \mathrm{c}=0.175$ yang akan menyebabkan kegagalan pada pipa berupa mixed mode collapse yang artinya akan tejadi patah campuran antara getas dan plastic. Hal ini tejadi dikarenakan posisi $\mathrm{Kr}$ dan $\mathrm{Lr}$ menurut FAD berada pada daerah mixed mode failure diatas assesment line. Sedangkan untuk dimensi cacat yang lebih kecil aman.

\section{FAD Kondisi Pembebanan Maksimum $\left(\sigma_{\text {tarik }}=\right.$ 82842.5 psi) \\ Hasil dan perhitungan $\mathrm{Kr}$ dan $\mathrm{Lr}$ dapat} dilihat pada tabel 4 .

Tabel 4. Perhitungan Kr dan Lr Pada Pembebanan Maksimum

\begin{tabular}{cccc}
$\begin{array}{c}\text { crack } \\
\text { junction }\end{array}$ & $\mathbf{a} / \mathbf{2 c}$ (inch) & $\mathbf{K r}$ & $\mathbf{L}_{\mathbf{r}}$ \\
\hline $\mathrm{A}$ & 0.0469 & 1.8252 & 1.2686 \\
$\mathrm{~B}$ & 0.0938 & 3.5470 & 1.2686 \\
$\mathrm{C}$ & 0.1406 & 5.8913 & 1.2686 \\
$\mathrm{D}$ & 0.1750 & 10.2321 & 1.2686 \\
\hline
\end{tabular}

Dari FAD di atas didapatkan bahwa, pipa gas bawah laut tersebut sangat tidak aman untuk digunakan beroperasi kembali. Hal ini terjadi karena nilai dari semua $\mathrm{Kr}$ yang ada jauh diatas assesment line dari $\mathrm{FAD}$, sehingga untuk semua dimensi cacat las pasti akan mengalami kegagalan.

\section{KESIMPULAN}

Dari penelitian ini diambil beberapa kesimpulan, antara lain:

- $\quad$ Pada saat pembebanan minimum $\left(\sigma_{\text {tarik }} 8284.25\right.$ psi), dengan FAD maka pipa yang mempunyai cacat $\mathrm{a} / 2 \mathrm{c}=0.1750$ in akan menyebabkan pipa patah getas, karena pertemuan $\mathrm{Kr}$ dan $\mathrm{Lr}$ berada diatas assesment line pada daerah brittle failure. Sedangkan untuk dimensi crack yang lain masih cukup aman.

- Pada saat pembebanan menengah $\left(\sigma_{\text {tarik }}=\right.$ $41421.25 \mathrm{psi}$ ), dengan dimensi crack $\mathrm{a} / 2 \mathrm{c}=$ 0.1750 in, maka pipa akan mengalami patah campuran antara patah getas dan plastis, karena pertemuan $\mathrm{Kr}$ dan $\mathrm{Lr}$ berada diatas assesment line pada daerah mixed mode failure. Sedangkan untuk dimensi crack yang lain masih cukup aman.

- Pada saat pembebanan maksimum $\left(\sigma_{\text {tarik }}=\right.$ 82842.5 psi), dengan dimensi crack yang paling kecilpun, karena pengaruh beban yang cukup tinggi, maka pipa tersebut tidak lagi aman. Karena posisi pertemuan $\mathrm{Kr}$ dan $\mathrm{Lr}$ berada jauh diatas asesment line.

\section{DAFTAR PUSTAKA}

1. Anderson, T.L., 1995. Fracture Mechanics : Fundamental and Aplication, CRC Pers. USA.

2. ANSYS 8.0 documentation, Ansys theory reference.

3. Anonim, 1998. Diktat Pipeline Inspection BP MIGAS. Jakarta

4. API 5L., 2000. Specification for Line Pipe Forthy Second Edition. USA

5. API 1104., 2000, Recommended Practice For Standart of Welding Pipelines and Related Facilities $-16^{\text {th }}$ Edition. USA

6. Barsom, J.M \& Rolfe, S.T. 1987. Fracture and Fatique control in Structure, PreticeHall, Inc., Englewood, New Jersey 07632.

7. Gourd, L. M. 1980. Principle of Welding Technology, Edward Arnold (publisher) Ltd, London.

8. Hertzberg, W.R, 1937. Deformation and Fracture Mechanics of Engineering Materials, John Wiley \& sons, Inc.New York

9. Raswari. 1986. Teknologi dan Perencanaan Sistem Perpipaan, UI Press, Jakarta.

10. Soegiono 2004. Teknologi Produksi dan Perawatan Bangunan Laut, Airlangga University Press, Surabaya.

11. Soeweify, 1985. Perkiraan Fatigue Life dari Sambungan Las yang mempunyai Cacat Dalam berbentuk Elip, Seminar Pengembangan Teknologi Pengelasan - FTK ITS, Surabaya.

12. Taufik, A. 2004. Paper : Aplikasi Failure Analysis Diagram untuk Mengevaluasi Integritas Mekanik Pipa Transmisi Gas yang mengandung Cacat pada Lasan, Indonesian Pipeline Technology, ITB, Bandung.

13. Widharto, Sri. 2003. Petunjuk Kerja Las, Pradnya Paramita, Jakarta.

14. Ketut S, P.hD, 2006, Seminar Nasional Teori dan Aplikasi Teknologi Kelautan VI, PP106-117. Surabaya. 